\title{
Flexible Conductive Films Fabricated Using Exfoliated Graphite and Nanocellulose
}

\author{
Colman MME ${ }^{1 *}$, Canesqui MA², Tasic $\mathrm{L}^{3}$, Bartoli JR ${ }^{1}$ and Moshkalev $\mathrm{S}^{2}$ \\ ${ }^{1}$ Faculty of Chemical Engineering, State University of Campinas, Brazil \\ ${ }^{2}$ Semiconductor and Nanotechnology Components Center, State University of Campinas, Brazil \\ ${ }^{3}$ Department of Organic Chemistry, State University of Campinas, Brazil \\ *Corresponding author: Uwe Reischl, Professor, Department of Community and Environmental Health, Boise State University, Idaho, USA

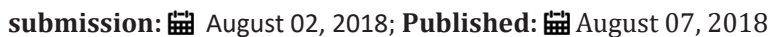

\begin{abstract}
Development of nanostructured composite materials based on exfoliated graphite and nanocellulose for applications in flexible electronics including smart textiles is described. High electrical conductivities, near $140 \mathrm{kS} / \mathrm{m}$, comparable with conventional conductive materials like metals, as well as good mechanical properties, were measured for the graphite-cellulose compound.
\end{abstract}

\section{Introduction}

Flexible highly conductive thin film materials have been gaining growing attention due to numerous possible applications in flexible electronics including for smart textiles in particular for local heating and sensing [1]. Graphene is a new promising highly conductive and flexible material that has been the target of numerous theoretical and experimental researches, due to the excellent physical and chemical properties [2] and a great potential in many fields of application such as composite materials, electronic devices, energy storage, batteries, capacitors and sensors. However, a limiting factor is still the lack of effective methods for mass production of graphene [3]. Here we present one approach developed to overcome this limitation, based on low cost processing method for exfoliation of graphite to produce a few and multilayer flexible graphene sheets that could be used in an industrial scale. It is known that the well-known graphite exfoliation method based on a chemical mechanism, introduces numerous defects in its structure, which could compromise its mechanical and electrical performance [4]. On the other hand, mechanical properties of films based solely on exfoliated graphene are not good enough for applications like in smart textiles when repetitive stretching and bending are applied. Thus graphene-based composite materials including high aspect (length/diameter) ratio reinforcing elements could be a choice for this particular application. Cellulose is a low-cost, abundant, biocompatible biopolymer whose modification is easy and ecofriendly. Due to interesting mechanical properties and high aspect ratio this material can also be used as reinforcements for adhesives, components of electronics devices, textiles, among others [5]. However, it is a hydrophobic material, so it does not dissolve in water or hydrophilic solvents. Medronho et al. [6] emphasized that cellulose is soluble in solvents with intermediate properties such as $\mathrm{N}$-methylmorpholine $\mathrm{N}$-oxide and ionic liquids. In this way, cellulose can act as an exfoliation agent on the surface of graphite, stabilizing its aqueous dispersions [3]. Summarizing, exfoliated graphite emerged as an excellent component to obtain new conductive nanostructured materials and cellulose, in turn, has an excellent potential for less aggressive eco-friendly graphite exfoliation and preparation offlexible conductive films for numerous applications in smart textiles.

\section{Methodology}

The preparation of the graphite exfoliation was performed according to Ferreira et al. [3] and divided into two stages. Two types of graphite were used: non-expanded and expanded, provided by the Nacional de Grafite Ltda (Brazil). Three different types samples were prepared: (a) $1 \mathrm{NC}$, graphite non-expanded; (b) $2 \mathrm{NC}$, graphite expanded and (c) $3 \mathrm{NC}$, graphite expanded with acrylic emulsion binder. The first step fabrication consisted of the addition of the cellulose obtained by Mariño et al. [7] in 7\% aqueous sodium hydroxide solution ( $\mathrm{NaOH}$, Sigma-Aldrich) and sonicated by a $7 \mathrm{~mm}$ diameter probe at $70 \%$ amplitude and $90 \mathrm{~W}$ (Hielscher, Model UP400ST) with pulses of 2s, in an ice bath. This graphite-cellulose mixture remained in the freezer for 1 hour at -6 ${ }^{\circ} \mathrm{C}$. The second step was to prepare the graphite in $7 \%$ aqueous $\mathrm{NaOH}$ solution. Subsequently, the two phases were mixed and shaken in a water bath (Dubnoff) with mechanical stirrer (Marconi) at $133 \mathrm{rpm}$ for $18 \mathrm{~h}$. Another expanded graphite-cellulose compound 
containing 15\% acrylic polymeric binder (Printofix CA, Archroma) was prepared in relation to the expanded graphite - cellulose mass. A homogenizer (Ultra Turrax) was used to mix the solution of this sample (3 NC).

The graphite-cellulose thin films were obtained by vacuum filtration of solutions using qualitative paper filters (Calgon), $7 \mathrm{~cm}$ in diameter, after the stirring step. The samples were then kept for $24 \mathrm{~h}$ at room temperature for drying and then compacted by calendering at $120{ }^{\circ} \mathrm{C}$ and opening between calender cylinders from 0.35 to $0.45 \mathrm{~mm}$. Nanostructured composites of graphite and cellulose nanosheets were obtained for electrical and flexible conductive films. The thicknesses of the so prepared films were measured with Mitutoyo micrometer. Electrical characterization of films was performed using the van der Pauw four-probed method (1959) with Agilent Instruments, B2912A Series Low Noise Power
Source equipment. Morphological analyzes of the films were made via Scanning Microscopy, SEM (Hitachi, S-3400N).

\section{Results and Discussion}

Figure 1 shows the films produced by vacuum filtration of the samples $1 \mathrm{NC}, 2 \mathrm{NC}$ and $3 \mathrm{NC}$ with the graphite non-expanded, expanded and acrylic emulsion binder expanded, respectively. The samples $1 \mathrm{NC}$ and $2 \mathrm{NC}$ presented improved mechanical properties due to addition of cellulose; however, the $3 \mathrm{NC}$ sample with higher content of graphite and polymeric binder showed no mechanical stability [8]. Then, to recompose the mechanical integrity of the graphite with the nanocellulose, $15 \%$ acrylic emulsion binder was added in relation to the mass of graphite and nanocellulose, and then added in $200 \mathrm{~mL}$ of $7 \% \mathrm{NaOH}$ aqueous solution. It was homogenized in Ultra Turrax for 20 minutes and 6000rpm, after this process the film was prepared (Figure 1C).

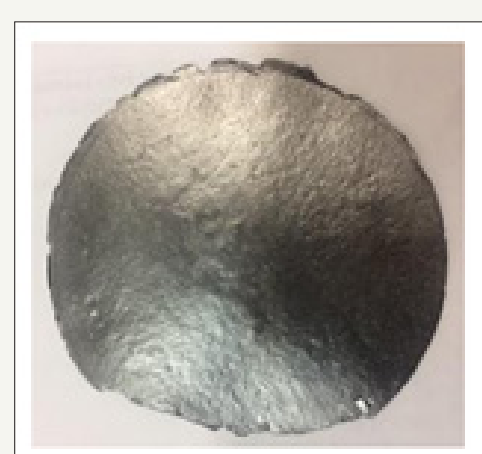

(a)

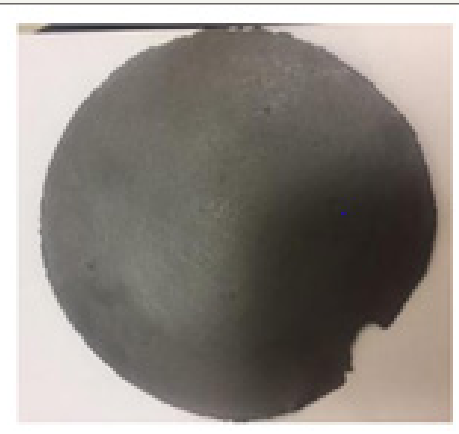

(b)

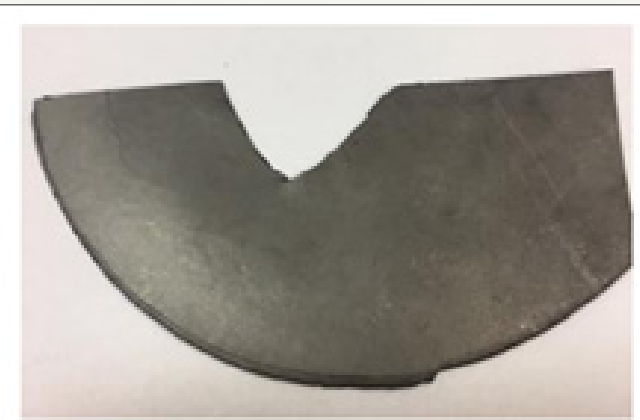

(c)

Figure 1: Conductive nanosheets: 1NC, graphite non-expanded (a); $2 \mathrm{NC}$, graphite expanded (b) and

$3 \mathrm{NC}$, graphite expanded with acrylic emulsion binder (c).

The conductivities of the samples were measured before and after calendaring that resulted in strong reduction of the resistivity (increase of the conductivity). For the samples 1NC and 2NC the best conductivities are typical for conductive materials, being near $140 \mathrm{kS} / \mathrm{m}$ (resistivity of $\left.0.7 \times 10^{-4} \mathrm{Ohm} . \mathrm{cm}\right)$ and $10 \mathrm{kS} / \mathrm{m}\left(1.0 \times 10^{-}\right.$ ${ }^{2} \mathrm{Ohm} . \mathrm{cm}$ ), for the thicknesses of $10^{-2}$ and $8 \times 10^{-2} \mathrm{~mm}$, respectively. Lower values the higher values of the $3 \mathrm{NC}$ sample resistivities (conductivity $5 \mathrm{kS} / \mathrm{m}$ to $0.2 \mathrm{~mm}$ ) are due in part to a certain porosity observed in the material, in addition to the use of the polymeric dielectric binder. After calendaring, the best resistivities were measured for sample 1NC, being near, while higher values were obtained for samples $2 \mathrm{NC}$ and $3 \mathrm{NC}$, being and $2 \times 10^{-2} \mathrm{Ohm} . \mathrm{cm}$, respectively. It was noticed that the malleability of the samples was favored by adding of cellulose, as can be seen in Figure 2 .

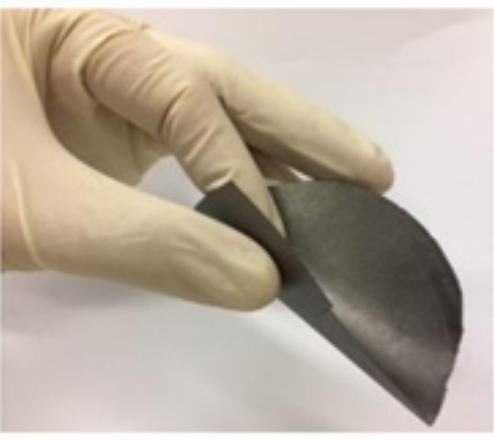

(a)

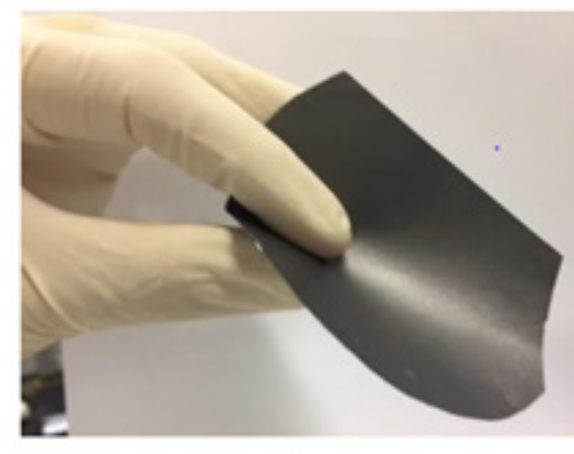

(b)

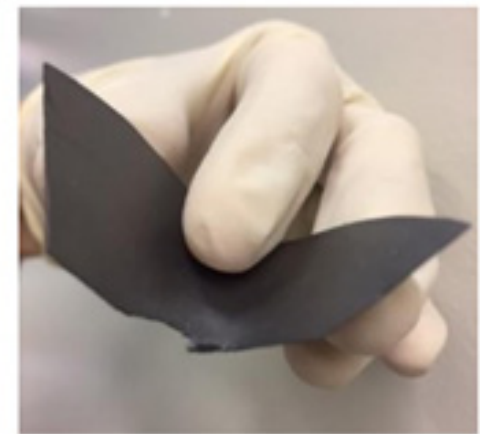

(c)

Figure 2: Conductive films: 1NC, graphite NF-C type (a); 2NC, graphite expanded (b) and 3NC, graphite expanded with acrylic emulsion binder (c). 
The micrographs (SEM, Figure 3) show random orientation of the graphite sheets within thefilm. However, the 1NC sample, with non-expanded graphite, showed a better uniformity and compact morphology, after the calendering process, than the $2 \mathrm{NC}$ and $3 \mathrm{NC}$ samples. The latter, with expanded graphite, showed a certain porosity in the surface of the samples, justifying lower conductivity in this material. In the $3 \mathrm{NC}$ sample with acrylic emulsion binder (Figure 3C) it is possible to observe the cellulose inclusions on the surface of the composite.

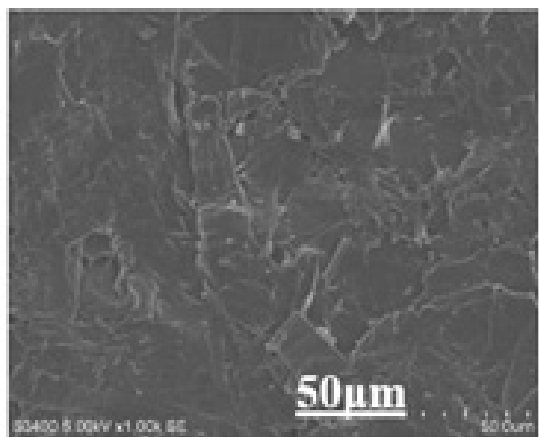

(a)

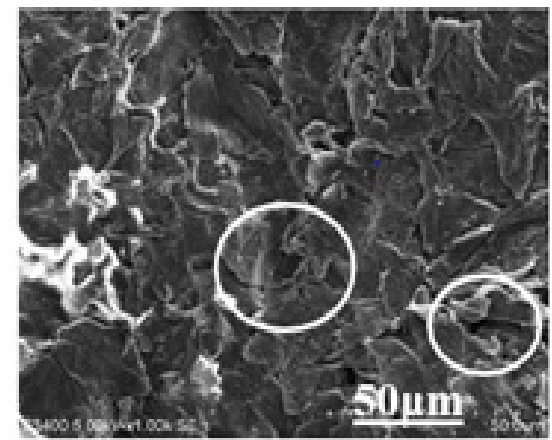

(b)

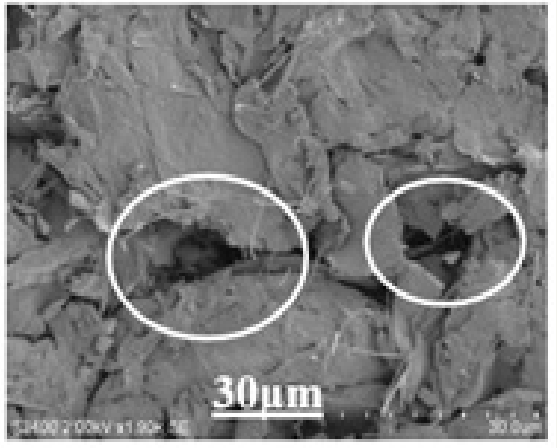

(c)

Figure 3: SEM images of samples: $1 \mathrm{NC}, 2 \mathrm{NC}$, and $3 \mathrm{NC}$ with acrylic emulsion binder and cellulose.

\section{Conclusion}

The use of cellulose was favorable for imporvement of mechanical properties (malleability) of nanographite flexible fims, both for expanded graphite or non-expanded graphite. However, the larger amount of expanded graphite relative to cellulose led to a more fragile material, even adding an acrylic emulsion binder. High electrical conductivities were found in the cellulose and non-expanded graphite composites after calendering process that reduced the thickness and improved the contact between the graphite nanofoils, with more uniform morphology seen by SEM microscopy. The best results in electrical conductivity obtained here, $\sim 140140 \mathrm{kS} / \mathrm{m}$, are comparable with those for conventional conductive materials like metals. High electrical conductivity and good mechanical properties of the present graphite-cellulose composite material open way to applications in smart textiles in particular for local heating, mechanical sensing and RFID.

\section{References}

1. Liu Y, Sun B, Li J, Cheng D, An X, et al. (2018) Aqueous dispersion of carbon fibers and expanded graphite stabilized from the addition of cellulose nanocrystals to produce highly conductive cellulose composites.
ACS Sustanaible Chem Eng 6(3): 3291-3298.

2. Du W, Jiang X, Zhub L (2013) From graphite to graphene: direct liquidphase exfoliation of graphite to produce single- and fewlayered pristine graphene. J Mater Chem A 1(36): 10592-10606.

3. Ferreira ES, Da Silva DS, Burgo TAL, Batista BC, Galembeck F (2017) Graphite exfoliation in cellulose solutions. Nanoscale 9(29): 1021910226.

4. Stankovich S, Dikin DA, Piner RD, Kohlhaas KAA, Kleinhammes A, et al. (2007) Synthesis of graphene-based nanosheets via chemical reduction of exfoliated graphite oxide. Carbon 45(7): 1558-1565.

5. Morais JPS, De FRM, Moreirade SFM, Nascimento LD, Do NDM, et al. (2013) Extraction and characterization of nanocellulose structures from raw cotton linter. Carbohydrate Polymers 91(1): 229-235.

6. Medronho B, Romano A, Miguel MG, Stigsson L, Lindman B (2012) Rationalizing cellulose (in)solubility: reviewing basic physicochemical aspects and role of hydrophobic interactions. Cellulose 19(3): 581587.

7. Mariño M, Lopez DSL, Duran N, Tasic L (2015) Enhanced materials from nature: nanocellulose from citrus waste. Molecules 20(4): 5908-5923.

8. Van-Der PLJ (1959) A method of measuring the resistivity and hall coefficient on lamellae of arbitrary shape. Philips Technical Review 20: 220-224.
Creative Commons Attribution 4.0 International License

For possible submissions Click Here Submit Article

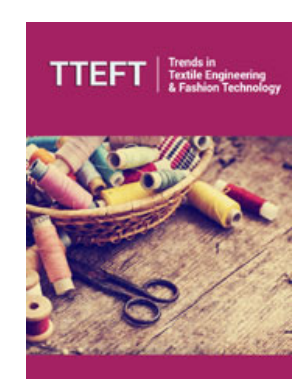

Trends in Textile Engineering \& Fashion Technology

\section{Benefits of Publishing with us}

- High-level peer review and editorial services

- Freely accessible online immediately upon publication

- Authors retain the copyright to their work

- Licensing it under a Creative Commons license

- Visibility through different online platforms 